\section{Predatory journals: fortify the defences}

Ongoing initiatives are crucial for keeping researchers informed about predatory journals and the fraudulent strategies they use to recruit submissions (see P. Sorokowski et al. Nature 543, 481-483; 2017). For example, these journals will often add names of real researchers to their editorial boards for credibility, but without consent. We urge all scholarly publishers to join the fight against such practices.

Beall's online list of potential, possible or probable predatory open-access publishers, now discontinued, was invaluable for dealing with harassment by predatory journals. An anonymous website now provides a record of the entire list (see go.nature.com/2ok23zq), but it will need to be continually updated using Beall's criteria if it is to be effective.

Publishers could help by providing guidelines for choosing reliable journals in which to publish. An example is the 'Think. Check. Submit' initiative (go.nature.com $/ 2 \mathrm{plm} 8 \mathrm{kd}$ ), which is supported by respected organizations and publishers such as the Directory of Open Access Journals and Springer Nature. Vinicius J. Giglio Federal University of Rio de Janeiro, Brazil. Osmar J. Luiz Charles Darwin University, Darwin, Australia. vj.giglio@ufrj.br

\section{Predatory journals: Beall's List is missed}

Beall's List of predatory publishers, now withdrawn, was instrumental in the fight against the dubious practices of some online open-access science journals (see P. Sorokowski et al. Nature 543, 481-483; 2017). To borrow a metaphor from James Woolsey, director of the CIA when the Soviet Union was collapsing: 'we live now in a jungle filled with a bewildering variety of predatory publishers. And Beall's List was easier to keep track of.'

The list was a government standard for checking academic publishers and journals worldwide. We now urgently need other standards to take its place. Ethics committees must draw up guidelines for distinguishing reputable from disreputable journals. And citation databases such as Scopus and the Web of Science need to weed out journals suspected of predatory practices to prevent authors from unwittingly submitting manuscripts to them. Wadim Strielkowski Cambridge Judge Business School, Cambridge, UK. ws342@cam.ac.uk

\section{Gentler alternatives to chips in the brain}

As physicians and neuroscientists, we are concerned about the clinical and scientific limitations of chip-in-the-brain technology. Until these problems are overcome, we argue that less invasive methods could be used.

Implantation of an electronic chip requires opening the skull and inserting the chip into the cortex, where it records spikes from a few dozen neurons (out of millions) for an unpredictable length of time (often less than a year). This technique has been used, for example, to restore motor function after spinal-cord injury in humans (C. E. Bouton et al. Nature 536, 247-250;2016) and primates (M. Capogrosso et al. Nature 539, 284-288; 2016). In our view, a non-invasive signal could have controlled the movements under study with comparable efficacy.

Many non-invasive brainderived signals can be used to activate paralysed muscles directly. These signals can be accessed readily throughout the body - for example, by scalp electroencephalograms or by electromyography of muscles.
Currently, the risk-benefit ratio of these techniques is more favourable in this context than the invasive approach, particularly when significant functions remain intact post-injury (see go.nature.com/2ohpfmw).

This may change with advances in technology, when the risk-benefit ratio of inserting a chip into the brain improves sufficiently to justify clinically oriented research that can also advance our knowledge of cortical motor control and/or recording technology.

Robert Ajemian* Massachusetts Institute of Technology,

Cambridge, Massachusetts, USA. ajemian@mit.edu

${ }^{*}$ On behalf of 6 correspondents (see go.nature.com/2oq1xgw for a full list).

\section{Help bigger palm oil yields to save land}

Technological innovation in oilpalm farming could help both to boost yields of palm oil and to reduce deforestation, but only if higher productivity causes palmoil prices to drop sufficiently to discourage additional cultivation (see Nature 543, 306-308; 2017). If prices stay high, the demand for land is likely to go up in the push for ever-larger profits.

Models that integrate economic and biophysical processes (IMPACT: see go.nature.com/2ojvowt) project a near doubling of oil-palm acreage in the next 40 years, an expansion compatible with the additional 19.3 million hectares estimated for sustainable oilpalm cultivation in the future (J. Pirker et al. Global Environ. Change 40, 73-81; 2016).

The widespread adoption of a technology that could, say, double the production of cheaper oil stands to reduce these land requirements markedly.

However, the processes of innovation, adoption and market adjustment are not instantaneous or uniform across farmers and regions. During the transition, early adopters of innovative technologies will gain a competitive advantage, and thus an incentive to expand their cultivation area - potentially at the expense of environmentally sensitive land. Yield-boosting innovations should therefore be accompanied by careful monitoring and regulation of land conversion.

Alessandro De Pinto, Keith

Wiebe International Food Policy Research Institute, Washington DC, USA.

Pablo Pacheco Center for International Forestry Research, Bogor, Indonesia.

a.depinto@cgiar.org

\section{An old clue to the secret of longevity}

Epidemiologists are seeking to identify the lifestyle and environmental factors that make the Greek inhabitants of Ikaria, a small island in the Aegean Sea, one of the world's longest-lived populations (see go.nature. com/2nzec7y and P. Pietri et al. J. Am. Coll. Cardiol. 66, 1842-1843; 2015). Centenarians were common on the island even 400 years ago, when a local archbishop captured essential elements of their longevity.

In A Description of the Present State of Samos, Nicaria, Patmos, and Mount Athos (Pitt, 1678), Joseph Georgirenes remarks on the longevity of people in Nicaria (now known as Ikaria), attributing it to the air and water, community spirit, sparse diet and inherited disposition. He declared it "a great wonder, considering how hardily they live".

He concludes: "Thus, you have an account of a small island, the poorest and yet the happiest of the whole Aegean Sea."

Panagiota Pietri, Theodore Papaioannou, Christodoulos Stefanadis Athens Medical School, Athens, Greece. stefanadischristodoulos@gmail. com 